\title{
EDITORIAL
}

\section{UN MUNDO DE DISPARIDADES}

\section{A WORLD OF DISPARITIES}

\author{
Pedro Tomé ${ }^{1}$ \\ Instituto de Lengua, Literatura y Antropología, CSIC \\ Francisco Ferrándiz ${ }^{2}$ \\ Instituto de Lengua, Literatura y Antropología, CSIC
}

\begin{abstract}
Cómo citar este artículo / Citation: Tomé, Pedro y Francisco Ferrándiz. 2019. "Un mundo de disparidades». Disparidades 74(1): e001. doi: <https://doi.org/10.3989/dra.2019.01.001>.

RESUMEN: Este texto establece las claves principales de la línea editorial que Disparidades. Revista de Antropología, cuyo nombre estrena en este número, llevará en los próximos años. El cambio de denominación responde a un largo proceso de debate entre los miembros del Consejo de Redacción en el periodo 2015-2018, y tiene como finalidad profundizar en la armonización de la revista con las transformaciones de la disciplina antropológica en las últimas décadas.
\end{abstract}

PALABRAS CLAVE: Revistas académicas; Editoriales académicas; Antropología social y cultural.

ABSTRACT: This text establishes the key editorial principles for the forthcoming years of the academic journal Disparidades. Revista de Antropología, which has changed its name in this issue. The name change responds to a long debate among the members of the Editorial Committee during the period 2015-2018, and has as its main purpose the ongoing harmonization of the journal with the transformations taking shape within anthropology in the last few decades.

KEYWORDS: Academic Journals; Academic Presses; Sociocutural Anthropology.

Copyright: (C) 2019 CSIC. Este es un artículo de acceso abierto distribuido bajo los términos de la licencia de uso y distribución Creative Commons Reconocimiento 4.0 Internacional (CC BY 4.0).

1 Correo electrónico: pedro.tome@csic.es. ORCID iD: <https://orcid.org/0000-0001-5380-5994>.

2 Correo electrónico: f.ferrandiz@csic.es. ORCID iD: <http://orcid.org/0000-0002-4095-6344>. 
Las sucesivas crisis que la antropología como disciplina ha superado desde sus inicios la han llevado desde el intento decimonónico de derivar una sucesión en la evolución de las culturas mediante la investigación de campo en las que se consideraban «primitivas contemporáneas», hasta el progresivo análisis de las complejas transformaciones sociales inherentes a los procesos globalizadores del siglo XXI (Eriksen 1995). El desbordamiento, hace ya décadas, del territorio de los exotismos más o menos cercanos en el espacio y el tiempo, la constatación de «que el mundo de la humanidad constituye un total de procesos múltiples interconectados» (Wolf 1987: 15) y de que buena parte del conocimiento etnográfico esencial de la antropología había sido producido en situaciones coloniales (Stocking 1991), permitió atravesar, no sin problemas y agitados debates, una «crisis de representación» (Marcus y Fischer 1986) y otras asociadas o derivadas de ella. Gracias en parte a que, como señala Marilyn Strathern en la entrevista que se incluye en este mismo volumen, «era parte de las formación antropológica aprender a criticar las categorías de análisis dadas (no había nada que no se prestase a un examen crítico)» (Corsín 2019). A ello, sin duda, habría que añadir que la costumbre antropológica de "reflexión autocrítica y de observación de las concepciones locales del espacio y del tiempo le permite adaptarse a los cambios de la historia y tomar en cuenta las nuevas modalidades de simbolización o desimbolización que obran en el conjunto planetario» (Augé 2007: 21). Es justamente esta capacidad de metamorfosis lo que ha posibilitado tanto la irrupción de nuevos modelos teóricos y metodológicos más abiertos y flexibles que buscan dar respuesta a las diferentes transformaciones en las vicisitudes socioculturales, como la profundización y ajustes en el perfil empírico de la investigación para fundamentar y dialogar con dichas ideas y teorías. Un doble ámbito en el que Disparidades. Revista de Antropología espera convertirse en un interlocutor mediante la publicación de «contribuciones innovadoras en la investigación antropológica, entendiéndola en un sentido teórico y metodológico amplio y plural [así como] artículos originales que, además de contribuir al conocimiento antropológico, enriquezcan el debate crítico entre los investigadores, con especial atención a las aportaciones teóricas y metodológicas, y a la etnografía de campo» (Disparidades 2019).
La línea editorial planteada cuando asumimos la gestión de la revista hace ya cuatro años (Tomé y Ferrándiz 2015) parte de la premisa de que, como señalamos hace unos meses en el último número de la RDTP, «la antropología no es solo una fuente de conocimiento empírico y teórico basada en la experiencia directa e intensiva de los entornos de investigación estudiados, sino también un agente crítico y transformador de la percepción de la complejidad de los procesos sociales, económicos, culturales y ambientales» (Tomé y Ferrándiz 2018: 292). Esto significa que el proyecto editorial que subyace a Disparidades propone generar paulatina y colectivamente un espacio fértil para la discusión en la disciplina, lo más abierto y vibrante posible, que sirva como «lugar de encuentro donde compaginar de manera imaginativa la versatilidad del repertorio metodológico de la antropología, su constante labor teórica y analítica, y su intuición para detectar y acotar los entornos de investigación relevantes en cada contexto»; un territorio, en definitiva, en el que pueda desarrollarse lo que Atkinson denominara «imaginación etnográfica» (ibid.: 293). En este sentido, recalcábamos que la antropología social y cultural contemporánea se ha consolidado como un

proceso emergente y denso en el que se establecen dinámicas de retroalimentación entre teoría y práctica, entre realidad y texto, entre diseños de investigación y situaciones cambiantes, entre escenarios de campo y aplicación de técnicas de investigación, entre la posición del investigador y la de los informantes, entre los investigadores y las audiencias de sus textos, etcétera» (ibid.: 293).

Es decir, es más sugerente y rica cuando se despliega en una suerte de "dialéctica de la sorpresa» (WiIlis y Trodman 2000) en la que el conocimiento que se genera dentro produce tanto análisis complejos como matizados - de pincel fino-, traduce críticamente y pone en cuestión el sentido común, desnuda las fake news, diversifica los puntos de vista, establece conexiones novedosas e imagina nuevos repertorios expresivos para comunicarse con sus diversos interlocutores (Ferrándiz 2011).

El proyecto editorial de Disparidades se enfrenta al reto de construir conocimiento analítico y crítico en el contexto altamente poliédrico y cambiante de sociedades profundamente aceleradas en las que la velocidad parece más relevante que saber dónde se va; sociedades atravesadas por fuerzas estructurales demoledoras y saturadas de (des)información en las 
que las experiencias del mundo están necesariamente «inacabadas» y al límite (Biehl y Locke 2017: 4). Estas condiciones de sobremodernidad, o de la enésima mutación del capitalismo global, exigen a quien quiere comprenderla e investigarla una gran versatilidad metodológica, capacidad constante de desbordamiento analítico, e imaginación para plantear nuevas propuestas comunicativas más eficaces. Así, en la medida en que nuestro objeto de estudio, y nuestra propia vida cotidiana, se acomoda paulatinamente a las múltiples formas de un prisma cada vez más complejo y repleto de deslumbrantes y superfluos centelleos donde se reflejan, dispersan, polarizan o desvanecen cada vez con mayor intensidad los procesos socioeconómicos y culturales, Disparidades pretende contribuir a detectar y desgranar en sus componentes básicos los variados disfraces y engañosas pistas de aquello que se aparece y se oculta simultáneamente tras esos reflejos y polarizaciones de prismas y antiprismas. Porque cuando se traspasan esos brillos y reverberaciones, cuando se descifra y atenúa el ruido, se descubre cómo el progresivo impacto de la digitalización en los comportamientos humanos se traduce, en buena medida, en la eliminación o debilitamiento de marcos conceptuales y de acción que se creían sólidos. No se trata de afirmar desmedidamente que todo se haya vuelto líquido o gaseoso o que los espejos en que nos miramos se disuelvan en nuestras manos, como le ocurría a la Alicia de Carroll: sigue habiendo rígidas estructuras e infraestructuras que se combinan y metamorfosean con otras plasmáticas, líquidas, gaseosas. Pero también ámbitos en los que no las hay o solo se muestran con una presencia débil o intermitente. Todas ellas integradas o desintegradas, concertadas, mezcladas, matizadas, entretejidas o discordantes. Pero cada vez más sutiles y más difícil de aprehenderse entre la maraña de juegos de manos y falsificaciones contantemente elaboradas y circuladas por spin doctors y fontaneros de toda índole.

Ocurre esto también en parte porque numerosos instrumentos de mediación en lo político, lo económico, lo social, lo cultural y, en definitiva, en todos los ámbitos de la vida humana, parecen haberse aminorado o desvanecido. No extraña pues, por poner un ejemplo, hallar procesos políticos de forma aparentemente clásica en los que, sin embargo, las organizaciones tradicionales tienen cada vez menos peso porque las redes sociales facilitan que los nuevos líderes, a veces con viejos intereses, se relacionen directamente con sus potenciales votantes sin nece- sidad de intermediación de partidos $u$ organizaciones que propicien un pensar colectivo. Procesos, por lo demás, en los que algunas de las conocidas resistencias al poder - «no existen relaciones de poder sin resistencias» (Foucault 1979: 171) - se presentan como «espontáneas» sin que tengan participación en ellas sindicatos $u$ otros colectivos que en otros tiempos habrían asumido un rol de representación (intermediación) preponderante. Pero si el político sin partido puede enfrentarse directamente - con el poder de las redes sociales y el desdén a los medios de comunicación tradicionales - a individuos (des) organizados, es porque la fragmentación social ha crecido a un ritmo que se antojaba impensable en muchos análisis de lo social realizados no hace tanto tiempo.

Precisamos pues de instrumentos, como Disparidades. Revista de Antropología, que contribuyan a comprender y observar de manera sistemática y crítica cómo la segmentación social -que no debe confundirse con la heterogeneidad inherente a lo social- se disemina por todos los ámbitos de la vida en común. También cómo avanza, de modo semejante a lo que acontece en lo político, en las interacciones económicas que, aún presentándose como colaborativas o propias de plataformas peer-to-peer, eliminan la mediación entre productor y consumidor para crear todo un mundo de precarizaciones -en lo laboral, en lo político, en lo simbólico, en lo identitario, en lo jurídico, en lo existencial...-. Interacciones enmascaradas bajo nuevos y sutiles conceptos cuyas significaciones complejas solo pueden ser desveladas a través de lo empírico y el cotejo cauteloso. Un análisis, por lo demás, que debe enfrentarse a la creciente especulación con «mercancías ficticias» en número inimaginable por Karl Polanyi (2016 [1944]), debido en parte a la progresiva sustitución de la condición de ciudadanía por la de «espectador» de un drama ajeno.

En este contexto de nuevas formas de dominación y extracción económica disfrazadas con lenguajes de diseño y mayor volatilidad de la experiencia, otro reto fundamental que Disparidades encara en el nuevo cuatrienio 2019-2022 como proyecto editorial es ampliar aún más el espectro de temáticas, autores, evaluadores y lectores actualmente presentes en la revista. En primer lugar, aunque la revista está abierta a todos los textos de carácter antropológico en un sentido amplio, priorizará la búsqueda de enfoques originales que contribuyan a extender el horizonte la 
disciplina desde el punto de vista formal, teórico, metodológico o incluso retórico. En segundo lugar, entre todos los miembros del equipo editorial buscaremos fórmulas para que un mayor número de potenciales autores, desde los investigadores emergentes a los más consolidados, encuentren en sus páginas un entorno al tiempo creativo y riguroso que haga que se sientan cómodos publicando en Disparidades. En este sentido, queremos contribuir de manera muy específica a profundizar los cruces y transvases entre las antropologías peninsulares y las de los diferentes países de América Latina. También a incorporar a autores que escriben habitualmente en otras lenguas $y$ que, o bien quieran publicar en castellano o, hasta el límite de nuestras posibilidades logísticas, prefieran comunicarse en sus idiomas preferentes para su trabajo. En tercer lugar, desde el Equipo Editorial de la revista se ha llevado a cabo un importante esfuerzo para aumentar el número de dictaminadores disponibles a la vez que se ha cambiado el modelo del formulario que se envía a los lectores externos de los artículos recibidos. En este marco, que a la vez que diversifica el trabajo profundiza en la evitación de prácticas endogámicas y la especialización en las solicitudes de revisión de textos, se ha incrementado la comunicación entre editores y evaluadores con el fin de enriquecer todo el proceso. Ambos aspectos análisis más especializados y mejores arbitrajes - revierten de manera muy directa en la calidad de la revista. Finalmente, todos estos cambios y mejoras tienen también como finalidad hacer la revista más relevante para un número creciente de personas, no solo profesionales de la disciplina, sino también aficionados o público en general. Secciones especiales como «Temas Emergentes» están especialmente diseñadas para incidir en debates de interés social, lo más cerca de los "temas de actualidad» que permite el formato de una revista académica y, como ya sucedió en uno de los casos (Suárez-Navaz 2015), tener impacto mediático y entrar a formar parte del debate público ${ }^{3}$.

No es casualidad que el primer número de la nueva denominación de la revista incluya una sección de «Temas Emergentes» sobre antropología feminista

3 Véase el blog de la Universidad del Barrio en el periódico en línea Público: <https://blogs.publico.es/universidad-delbarrio/2016/04/24/migracion-y-refugio-en-el-mediterraneo-los-agujeros-negros-de-la-modernidad-abren-la-seriede-temas-emergentes-en-la-revista-del-csic/>. Fecha de acceso: 25 mar. 2019.
(Gregorio 2019) -en un momento en el que el debate social y político sobre el feminismo y la violencia de género puede tomar en nuestro país una deriva muy preocupante-, y una entrevista en profundidad -que publicamos tanto en castellano como en inglés - con una de las antropólogas más influyentes de las últimas décadas cuya obra no ha sido apenas traducida al castellano, Marilyn Strathern (Corsín 2019). Como tampoco lo es que ya estén previstas secciones especiales dedicadas a analizar desde un punto de vista antropológico los efectos del cambio climático y las políticas globales en los nuevos contextos socioecológicos. $U$ otras cuestiones de actualidad, como la forma en que los pueblos indígenas enfrentan en el siglo XXI su relación con el resto del mundo generando sus propios medios de comunicación, las nuevas modalidades de desaparición de personas vinculadas no solo ya a procesos de represión política sino también a nuevas formas de delincuencia global, o los retos que la airbnbización y los nuevos modelos turísticos y de remodelación especulativa del tejido urbano plantean a muchas ciudades y a sus habitantes más precarios.

No es, sin embargo, intención de Disparidades convertirse en una suerte de zapping textual en el que pueda saltarse de un tema a otro como si quien se enfrente a los textos que publicaremos sea un mero espectador o espectadora a quien se le ofrece una variedad de temas que consumir. Sin abandonar la actualidad etnográfica, Disparidades hace del compromiso con la orientación pública uno de los pilares en que fundamentar su despliegue. Por ello mismo, abandona cualquier privilegiada atalaya desde la que observar la realidad sin inmiscuirse $y$, desde el rigor de la disciplina, opta por insertarse en las discusiones y diálogos que pretenden, mediante el análisis crítico, buscar soluciones a los problemas sociales y culturales con los que hombres y mujeres se enfrentan en sus entornos particulares. En todo caso, la participación en tales debates no implica situarse en una suerte de autoridad dispersa (Clifford 1996) que refleje un self igualmente disperso e inconstante (Tyler 1996: 313). Más bien, Disparidades, se autoconcibe como una bisagra que mantiene la puerta abierta a una pluralidad de textos y estilos de investigación derivados de investigaciones sólidas. Por tal motivo, pretende ser sobre todo un instrumento que permita profundizar en el conocimiento antropológico de unas sociedades y modalidades de experiencia cada vez más precarias e inasibles. 


\section{BIBLIOGRAFÍA CITADA}

Augé, Marc. 2007. "El objeto de la antropología hoy», en Psicoperspectivas 7(1): 9-21 Disponible en: <https://www.redalyc.org/pdf/1710/171016572002.pdf>. Fecha de acceso: 25 mar. 2019.

Biehl, Joao y Peter Locke. 2017. «Ethnographic Sensorium», en Joao Biel y Peter lock (eds.), Unfinished: The Anthropology of Becoming: 1-38. Durham/Londres: Duke University Press.

Clifford, James. 1996. "Sobre la autoridad etnográfica», en Carlos Reynoso (comp.), El surgimiento de la antropología postmoderna: 141-170. Barcelona: Gedisa.

Corsín, Alberto. 2019. «En relación: una entrevista con Marilyn Strathern». Disparidades. Revista de Antropología 74(1): e003. doi: <https://doi.org/10.3989/dra.2019.003>.

Disparidades. 2019. Disparidades. Revista de Antropología. Disponible en: <http://dra.revistas.csic.es/index.php/dra>. Fecha de acceso: 25 mar. 2019.

Eriksen, Thomas H. 1995. Small Places, Large Issues. Londres: Pluto Press.

Ferrándiz, Francisco. 2011. Etnografías contemporáneas: anclajes, métodos y claves para el futuro. Barcelona: Siglo XXI/ Anthropos.

Foucault, Michel. 1979. Microfísica del poder. 2. a ed. Madrid: Eds. La Piqueta.

Gregorio, Carmen (coord.). 2019. «Etnografías feministas». Disparidades. Revista de Antropología 74(1): e002a-e002f. doi:
Marcus, George y Michael Fischer. 1986. Anthropology as Cultural Critique: An Experimental Moment in the Human Sciences. Chicago: University of Chicago Press.

Polanyi, Karl. 2016 [1944]. La gran transformación. Crítica del liberalismo económico. Barcelona: Virus.

Stocking, George W. Jr. 1991. Colonial Situations. Essays on the Contextualization of Ethnographic Knowledge. History of Anthropology, vol. 7. Madison, Wisconsin: Wisconsin University Press.

Suárez-Navaz, Liliana (coord.). 2015. «Migración y refugio en el mediterráneo, más allá de las fronteras». Revista de Dialectología y Tradiciones Populares 70(2): 265-336. doi: <https://doi.org/10.3989/rdtp.2015.v70.i2>

Tomé, Pedro y Francisco Ferrándiz. 2015. «RDTP: nuevos tiempos, nuevas etnografías». Revista de Dialectología y Tradiciones Populares 70(1): 7-10.

Tomé, Pedro y Francisco Ferrándiz. 2018. «Mudar de nombre». Revista de Dialectología y Tradiciones Populares 73(2): 287294. doi: <https://doi.org/10.3989/rdtp.2018.02.001>

Tyler, Stephen. 1996. «La etnografía posmoderna: de documento de lo oculto a documento oculto», en Carlos Reynoso (comp.), El surgimiento de la antropología postmoderna: 297-313. Barcelona: Gedisa.

Willis, Paul y Mats Trondman. 2000. «Manifesto for Ethnography». Ethnography 1(1): 5-16.

Wolf, Eric R. 1987. Europa y la gente sin historia. México: Fondo de Cultura Económica. 